\title{
An Improved 9 Carat Yellow Gold Casting Alloy
}

\author{
Richard S. Jackson \\ Department of Metallurgy and Materials, The University of Aston in Birmingham, England

\begin{abstract}
Should new processes be adapted to existing materials or should new materials be developed in order to take full advantage of the potentialities of new processes? Jewellery investment casting is no exception to the rule that the second alternative is to be preferred.
\end{abstract}

Although. 9 carat gold-silver-copper-zinc alloys have been used for a very long time for the casting of jewellery, comparatively little information is available on the specific compositions in general use and the functions of the individual alloying elements. Whilst the gold content is held to within extremely narrow limits, the lower usually by law and the upper by economic necessity, the same may not be said for the other elements in the alloys. The proportions in which they are used may vary, even in alloys intended for the same purpose. Further, with the notably fragmented jewellery industry in many countries, formulation of alloys has often been in the hands of a small number of large bullion and jewellery producers who have devised their own compositions. There has been little incentive to rationalise compositions and there are no analytical or performance standards for carat gold alloys such as those which are generally accepted for so many base metal alloys used in industry.

While there is perhaps a lack of criticality in the compositions it is nevertheless a tribute to the skills within the jewellery trade that quite a wide range of alloys has been used satisfactorily. It does not follow, however, that all the presently available compositions are equally satisfactory and that with the trend towards investment castings, alloys originally formulated by trial and error for wrought manufacture will be equally suitable for use in cast form. This is particularly the case because of the differences in constitution and structure which may be displayed even by the same alloy in cast as opposed to wrought form.

Ideally, alloys for jewellery casting should meet the following requirements:

(1) High fluidity for filling intricate moulds

(2) A melting range within the capability of conventional melting and casting techniques and yet sufficiently high to allow soldering at a later stage

(3) An inherently fine grain to avoid hot tearing and undue susceptibility to the effects of harmful impurities during solidification and to minimise the 'orange peel' effect appearing on polished surfaces during deformation

(4) Adequate strength, ductility and hardness for any forming operations involved

(5) Freedom from oxide skins which could produce defective castings and impair solderability

(6) A low volatile element content in order to reduce metal losses and allow enamelling if desired

(7) Good colour and high reflectivity

Thus, the purpose of this work was to examine the extent to which presently used 9 carat alloys meet these requirements and, where possible, to suggest methods of improving them.

\section{The Constitutional Differences Between Wrought and Cast 9 Carat Gold Alloys}

Most low carat yellow gold alloys in common use are based on the gold-silver-copper ternary system with the addition of sufficient zinc to counteract the redness resulting from copper and achieve the yellow colour of high carat gold. Both the ternary and quaternary systems have been investigated, are described in detail in the literature (1 to 5) and feature in this issue of Gold Bulletin (6).

Zinc is extensively soluble in the three major components of the alloy and does not form separate phases at normal levels of addition. Constitutionally, it drastically reduces the extent of the copper-rich and silver-rich two phase region $(2,5,6)$. Further, it acts as a degasser and mild deoxidizer, increases ductility and may introduce sufficient lattice misfits to suppress the formation of ordered phases in the gold-and copper-rich alloys.

As a first step in the investigation, chemical analyses of over forty commercial 9 carat alloys from sources in the United Kingdom and elsewhere were carried out. A Cambridge Microscan V ElectronProbe Micro-Analyser (EPMA) was used since many of the samples were extremely small.

The composition (weight per cent) of most of the 9 carat yellow gold alloys was found to fall within the 
range $37.6 \mathrm{gold} / 9$ to 12 silver $/ 7$ to $11 \mathrm{zinc} / \mathrm{balance}$ copper, with the DF alloy which is popular in the United Kingdom containing approximately 10 silver $/ 7.5$ zinc/balance copper (Table I). A small group of yellow alloys however contained 0 to 1.5 silver and 7.5 to 10.5 zinc. The composition of gold alloys other than yellow is also shown in Table I.

The course of solidification during casting of a zinc-free 9 carat alloy containing 10 per cent silver and 52.5 per cent copper is shown in Figure 1. Solidification of this alloy whose average composition is at $\mathrm{O}$ starts with the formation of red dendrites of composition $\mathrm{C}$ which are rich in gold and copper. Freezing continues along the line CD with the outer layers of the dendrites becoming progressively enriched with silver, and as such increasingly lighter in colour, until the residual liquid reaches the eutectic composition $\mathrm{D}$ at which it solidifies as a duplex mixture of a red copper-gold phase of composition $\mathrm{E}$ with a whitish silver-gold phase of composition F. By contrast, an alloy of the same bulk composition $O$, wrought and annealed to equilibrium, would comprise only a mixture of red and whitish phases of compositions $A$ and $B$ respectively, in roughly a 4 to 1 ratio.

The colours attributed above to the individual areas in the microstructure are those taken from the colour ternary diagram $(6,7)$ rather than those seen under the optical microscope since colour assessment would be uncertain by this latter means.

Where zinc is added, as is the case with most 9 carat gold alloys, constitutional differences between the cast and wrought form of an alloy still exist. However, the narrowing of the two-phase region in the quaternary diagram reduces the differences in composition, in colour and in other properties between the silver-gold-and copper-gold-rich phases. On the other hand, in both the ternary and the quaternary alloys the solubilities of silver in the copper-rich and of copper in the silver-rich eutectic phases decrease with temperature and some degree of precipitation hardening is likely to result from slow cooling.
Table I

Commercial 9 Carat Gold Alloys

\begin{tabular}{c|c|c}
\multicolumn{3}{c}{ Concentration, weight per cent } \\
Most alloys & DF alloy & Some alloys \\
\hline $\begin{array}{c}9-12 \\
7-11\end{array}$ & 10 & $\begin{array}{c}0-1.5 \\
7.5-10.5 \\
\text { bal. }\end{array}$ \\
bal. & 7.5 & \\
\hline Red & 44.9 & Green \\
\hline $1-3$ & White & 7.5 \\
$0-2.5$ & $55-59$ & 17.5 \\
bal. & $3.5-60$ & bal. \\
& bal. & \\
\end{tabular}

Table II

Examples of Micro-Segregation in Two Cast Gold Alloys

\begin{tabular}{l|c|c|c|c}
\hline \multirow{2}{*}{ Area analysed } & \multicolumn{4}{|c}{ Compositon, weight per cent } \\
\cline { 2 - 5 } & $\mathrm{Au}$ & $\mathrm{Cu}$ & $\mathrm{Ag}$ & $\mathrm{Zn}$ \\
\hline Alloy No. 1 & & & & \\
Bulk composition & 39 & 46 & 10.4 & 7.5 \\
Dendrite centre & 60 & 31 & 7.5 & 3.7 \\
Dendrite outer region & 45 & 45 & 6.9 & 6.2 \\
Interdendritic region & & & & \\
$\quad$ (eutectic) & 36 & 32 & 25 & 6.2 \\
Alloy No 2 & & & & \\
Bulk composition & 44 & 49 & 1.5 & 7.8 \\
Dendrite centre & 71 & 23 & 1.4 & 2.6 \\
Interdendritic (Ag low) & 36 & 54 & 1.2 & 8.1 \\
Interdendritic (Ag high) & 12 & 47 & 2.6 & 9.1
\end{tabular}

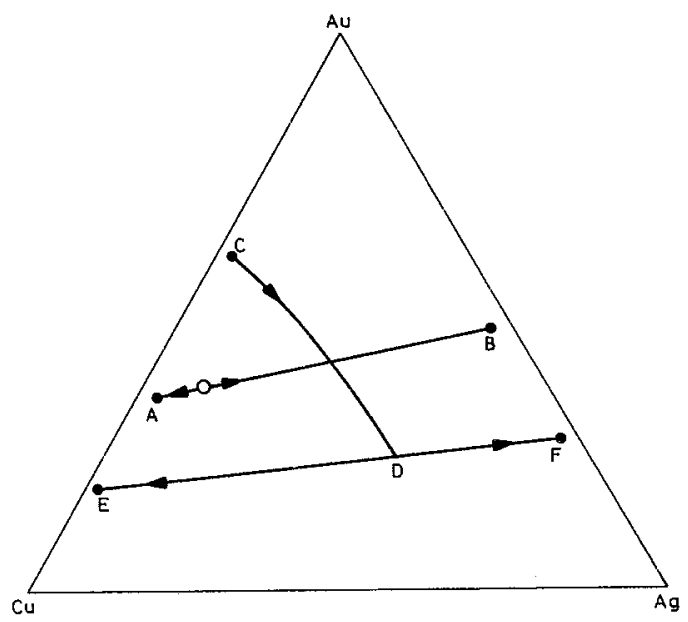

Fig. 1 Composition of the solid constitutents in a 37.5 gold $/ 10$ silver $/ 52.5$ copper weight per cent alloy

O Bulk composition

A Copper-rich phase in the alloy wrought and annealed to equilibrium

B Silver-rich phase in the alloy wrought and annealed to equilibrium

C Dendrite centres in the cast alloy

D Interdendritic eutectic in the cast alloy

E Copper-rich phase in the eutectic in the cast alloy

F Silver-rich phase in the eutectic in the cast alloy 
A measure of the microsegregation occurring in two commercial 9 carat yellow gold alloys as analysed by EPMA is given in Table II.

\section{Visual Appearance of Jewellery Alloys}

Colour and reflectivity are regarded as being among the most important attributes of a jewellery gold alloy after the legal and fabricating requirements have been satisfied. To a certain extent, these attributes are conflicting since colour saturation implies lack of reflectivity of complementary colours. The need for high reflectivity both on display and in corrosive and erosive service is fairly obvious for items whose main attraction is visual. Colour presents a much more complex and largely unexplored problem. Few buyers of jewellery may have consciously analysed their reasons for choice of colour. The opportunity was taken in this study to ascertain individual preferences of numerous lay persons presented with a choice of a large number of $20 \times 5 \mathrm{~mm}$ flat polished specimens in black metallographic mounts. It is interesting to note that the colour of the standard 18 carat alloy (75 gold/12.5 silver/12.5 copper, weight per cent) was the most popular, although a few preferred a slightly more pink colour associated with a higher copper content. In no case was pure gold chosen. Thus, in the present work the aim was to develop a 9 carat alloy that simulates the colour of the 18 carat standard alloy.

The overall appearance of multi-phase alloy might be expected to result from the combination of the colours and reflectivities of the individual microconstituents in proportion to their relative areas. However in a 9 carat alloy containing 10 per cent silver, 7.5 per cent zinc and balance copper, in the 'as cast' condition, the hardnesses recorded for the microconstituents were as follows:

$\begin{array}{lc} & \text { Micro-hardness } \\ & \mathrm{H}_{v} 50 \mathrm{~g} \\ \text { Dendrite centre } & 98 \\ \text { Dendrite outside } & 147 \\ \text { Eutectic region } & 180\end{array}$

During the burnishing of such an alloy, the soft goldcopper enriched dendrite centre phase is smeared over the harder phases thus obscuring the true microstructure and giving the appearance of an alloy of a higher gold content.

Experimental confirmation of this was obtained by using the EPMA at three electron accelerating voltages corresponding to increasing depth of surface penetration according to the Thompson-Whittington
Table III Composition of a Polished Sample of 9 Carat Yellow
ured by EPMA at Increasing Depths of Penetration

\begin{tabular}{|c|c|c|c|c}
\hline \multirow{2}{*}{$\begin{array}{c}\text { Depth of } \\
\text { penetration } \\
\mu \mathrm{m}\end{array}$} & \multicolumn{4}{|c}{ Composition, weight per cent } \\
\cline { 2 - 5 } & $\mathrm{Au}$ & $\mathrm{Cu}$ & $\mathrm{Ag}$ & $\mathrm{Zn}$ \\
\hline .456 & 39.8 & 43.9 & 10.4 & 7.0 \\
.81 & 37.5 & 44.4 & 10.3 & 7.8 \\
1.82 & 34.2 & 46.4 & 11.5 & 8.0
\end{tabular}

formula (8). A sample of 9 carat wrought alloy polished for metallography gave the analytical results recorded in Table III. The figures indicate that surface flow and gold enrichment affect a layer about $1 \mu \mathrm{m}$, or about 2500 atomic layers, thick. These effects are likely to be even greater in jewellery manufacture since polishing is considerably more vigorous than in metallographic sample preparation and is frequently preceded by an acid pickle which depletes the surface of base metal-rich (and hard) phases. Hence the colour of low carat jewellery articles may change with wear.

The surface reflectivity measurements of diamond polished $20 \times 5 \mathrm{~mm}$ samples of a large range of commercial and experimental alloys were carried out with a modified E.E.L. reflectivity meter in which tungsten filament incident and reflected light intensities are compared. For the purpose of this study no account was taken of colour. Thus the whiter silverrich alloys were favoured compared with the more deeply coloured ones. The results, some of which are summarised in Table IV, indicated that contrary to what is observed in pure gold (9), additions (up to 7.5 weight per cent) of silicon, lead, manganese, aluminium and nickel have little effect on the overall reflectivity of 9 carat yellow gold alloys. Therefore the necessity of visual attraction does not preclude the addition of these elements to jewellery alloys if they assist in meeting other desirable properties.

\section{Investigation of Alternatives to Existing 9 Carat Alloys}

The 9 carat alloys in common use generally consist of a mixture of gold with about 10 per cent silver diluted with a copper-zinc alloy of approximate ratio 5/1. With constituents in these proportions, a reasonable similarity to the colour of high carat yellow gold is achieved.

On the one hand, zinc appears to be the only suitable addition capable of turning the redness of copper to a golden yellow. On the other hand, despite its beneficial effect on castability, this volatile element has detrimental effects on enamelling and can be the cause of significant metal loss during casting or scrap 
Table IV

Reflectivity of Tungsten Filament Light by Various Metals and Alloys. Diamond Polished Surfaces

\begin{tabular}{l|c}
\hline Sample & $\begin{array}{c}\text { Reflectivity } \\
\text { per cent }\end{array}$ \\
\hline Pure gold & $60-65$ \\
18 ct standard alloy & 75 \\
9 ct DF alloy & $70-80$ \\
Silver-rich 9 ct alloy & $80-85$ \\
Pure copper & 75 \\
$18-8$ stainless steel & 65
\end{tabular}

remelting. However, zinc loss may be controlled by a small silicon addition. This is often done in brazing fillers where silicon also acts as a deoxidizer.

Silver is known to improve the hardness and corrosion resistance of low carat gold alloys. Its limit of solubility in the dendrites is about 5 per cent and there does not appear to be any a priori justification for its presence in higher concentrations.

Thus, the following modifications of the existing 9 carat yellow gold alloys were deemed worthwhile exploring: complete or partial substitution of zinc by another metal, introduction of silicon in zinccontaining alloys and reduction of the silver content.

With a view to overcoming the zinc volatility problem, aluminium, manganese, silicon, nickel, tantalum and palladium were substituted for it. In no case were the resulting alloys acceptable because of effects on colour and/or mechanical properties. Attention was therefore directed to small alloying additions of these metals to the basic gold-silver-copper-zinc system. A number of 9 carat experimental alloys was prepared with up to 0.5 per cent silicon and 1 to 2 per cent of either iron, manganese, cobalt or tantalum.
The mechanical properties of these alloys were determined using flat Hounsfield investment cast test bars $13 \times 3$ and either 1.25 or $2.5 \mathrm{~mm}$ thick. The tensile and hardness test results are shown in Table V. Small additions of silicon of around 0.25 per cent are seen to improve the ductility but examination of the bars with X-rays prior to testing indicated the presence of microporosity concentrated in highly detrimental layers when 0.5 per cent silicon was added. Silver is shown to have a hardening effect particularly from 0 to 5 per cent when all of it is dissolved in the dendrites. In the 5 per cent silver single phase alloy, small additions of tantalum, iron, manganese and cobalt were found to produce a significant improvement of both hardness and ultimate tensile strength.

The work hardening properties of several alloys are shown in Figure 2. Investment-cast ingots about $2.5 \mathrm{~mm}$ thick were cold rolled to 80 per cent reduction without edge cracking. Final hardnesses of the order of $250 \mathrm{Hv}$ were obtained. The hardening effect

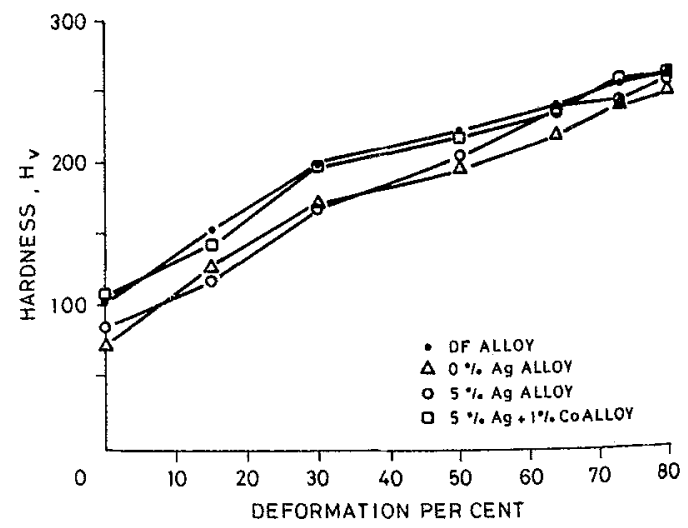

Fig. 2 Increase in hardness during cold-rolling of various 9 carat gold alloy compositions

Table $\mathrm{V}$

Mechanical Properties of Experimental Gold-Silver-Copper-Zinc-Silicon 9 Carat Cast Alloys (1.25 and $2.5 \mathrm{~mm}$ Thick Test Bars)

\begin{tabular}{|c|c|c|c|c|c|c|c|c|}
\hline \multicolumn{6}{|c|}{ Composition, weight per cent } & \multirow{2}{*}{$\begin{array}{c}\text { Hardness } \\
\qquad \mathrm{Hv}\end{array}$} & \multicolumn{2}{|c|}{$\begin{array}{l}\text { U.T.S./Elongation } \\
\mathrm{MPa} / \%\end{array}$} \\
\hline $\mathrm{Au}$ & $\mathrm{Ag}$ & $\mathrm{Zn}$ & $\mathrm{Si}$ & $\mathrm{Cu}$ & Others & & $1.25 \mathrm{~mm}$ & $2.5 \mathrm{~mm}$ \\
\hline 37.5 & 10 & 7.5 & 0 & 45.0 & & 115 & $305 / 31$ & - \\
\hline 37.5 & 10 & 7.5 & 0.25 & 44.75 & & 114 & $307 / 38$ & - \\
\hline 37.5 & 10 & 7.5 & 0.5 & 44.5 & & 112 & $228 / 6$ & - \\
\hline 37.5 & 0 & 11.5 & 0.25 & 50.75 & & 75 & $234 / 45$ & $261 / 48$ \\
\hline 37.5 & 5 & 9.5 & 0.25 & 47.75 & & 90 & $288 / 37$ & $327 / 53$ \\
\hline 37.5 & 10 & 7.5 & 0.25 & 44.75 & & 105 & $308 / 41$ & $333 / 50$ \\
\hline 37.5 & 5 & 7.5 & 0.25 & 49.75 & & 87 & $296 / 49$ & $320 / 56$ \\
\hline 37.5 & 5 & 7.5 & 0.25 & 47.75 & $2 \mathrm{Ta}$ & 88 & $333 / 33$ & $346 / 38$ \\
\hline 37.5 & 5 & 9.5 & 0.25 & 46.75 & $1 \mathrm{Fe}$ & 101 & $337 / 38$ & $325 / 45$ \\
\hline 37.5 & 5 & 9.5 & 0.25 & 46.25 & $1.5 \mathrm{Fe}$ & 106 & $303 / 17$ & $369 / 36$ \\
\hline 37.5 & 5 & 9.5 & 0.25 & 46.75 & $1 \mathrm{Mn}$ & 107 & $315 / 45$ & $324 / 49$ \\
\hline 37.5 & 5 & 9.5 & 0.25 & 46.75 & $1 \mathrm{Co}$ & 107 & $347 / 30$ & $383 / 30$ \\
\hline 37.6 & 5 & 10 & 0.38 & 47.02 & & 95 & $267 / 34$ & - \\
\hline
\end{tabular}


of silver, in solid solution at 5 per cent and partly as a eutectic phase at 10 per cent, was noticeable throughout the range of deformation. In contrast, that resulting from the presence of 1 per cent cobalt was minimal at high reductions.

These preliminary laboratory trials led to the selection of experimental alloys containing about 5 per cent silver and less than 0.5 per cent silicon for further investigation on a larger scale.

\section{Industrial Trials}

For the first large scale trials, 'trees' of ladies lightweight signet rings were cast using natural gas/air torch melting and centrifugal casting from 2 $\mathrm{kg}$ of water-grained alloy of the following nominal composition:

$\begin{array}{lc} & \text { Weight per cent } \\ \text { Gold } & 37.6 \\ \text { Silver } & 5.0 \\ \text { Zinc } & 10.0 \\ \text { Silicon } & 0.4 \\ \text { Copper } & 47.0\end{array}$

The gold was introduced in grain form (99.6 per cent gold), the silver also as grain, the copper as OFHC electrical wire and the zinc as a nominal $60 / 40$ brass master alloy of electrical copper and 99.95 per cent electrolytic zinc. The gold, copper and silver were melted first, after which silicon was added for deoxidation and finally the brass prior to the water graining operation. A small amount of borax was used as a cover flux. The melting and graining loss was 0.4 per cent but as a new crucible was used and no attempt was made to remove adherent metal prills, a lower loss could be expected in normal practice.

Three series of castings were made which gave the following metal loss and composition results:

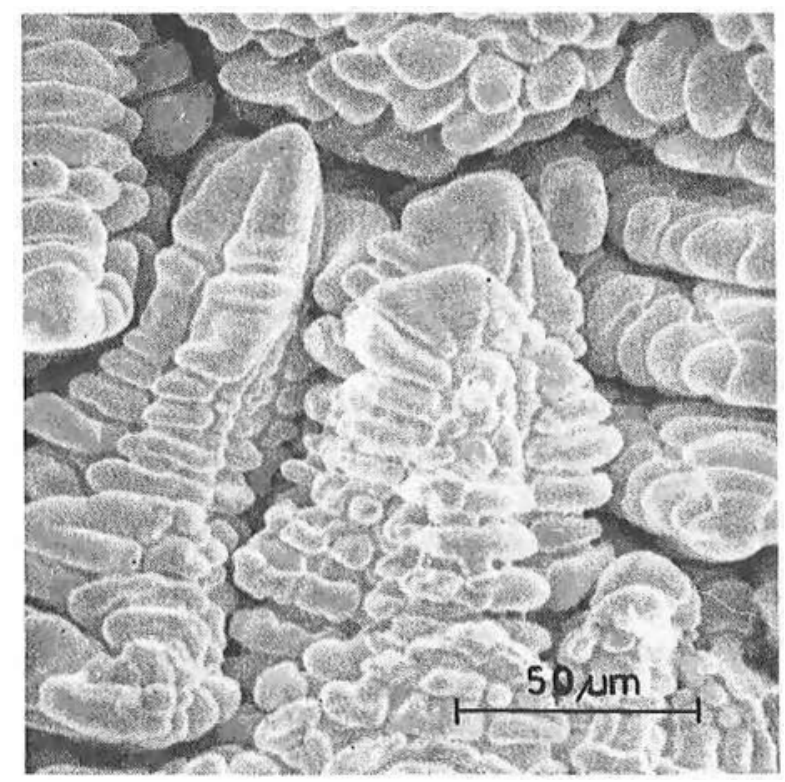

$\begin{array}{lccc}\text { Metal used } & \begin{array}{c}\text { Metal loss } \\ \%\end{array} & \begin{array}{c}\text { Compositon of castings } \\ \text { (wt. \%) }\end{array} \\ & & \mathrm{Zn} & \mathrm{Si} \\ \text { Virgin } & 1.9 & 10.1 & 0.38 \\ \text { 50/50 Virgin \& } & & & \\ \quad \text { recycled } & 0.41 & 10.2 & 0.39 \\ \text { Recycled } & 0.47 & 9.98 & 0.36\end{array}$

The losses of zinc and silicon were gratifyingly low and it appears that except where excessive temperatures are employed, there should be little change in composition of this alloy on re-melting.

The alloy behaved satisfactorily during melting and casting but a small number of rings cracked during soldering when 'sizing' the ring shanks. Investigation revealed that the grains were coarse and the structure was porous, there being insufficient low melting point liquid to fill the spaces between the dendrites as shown in the scanning electron micrograph in Figure 3. Brittle fracture occurred in the low melting point silver- and silicon-rich eutectic phase as confirmed by energy dispersive analysis. It appears that on reheating under stress during soldering, silver and silicon enriched liquid is formed which reduces the energy required for crack propagation. Clearly, improved soundness and freedom from cracking had to be achieved. This was done by raising the silver content slightly, to fill the inter-dendritic spaces, and by reducing the silicon to a level where it is all held in solid solution.

Further tests were performed by re-alloying to the following nominal compositions:

\begin{tabular}{lrr} 
& \multicolumn{2}{c}{ Weight per cent } \\
Gold & 37.7 & 37.7 \\
Silver & 7.0 & 7.0 \\
Zinc & 9.0 & 6.0 \\
Silicon & 0.2 & 0.2 \\
Copper & 46.1 & 49.1
\end{tabular}

The two alloys behaved excellently on casting and were free from the inadequacies observed previously. The low zinc alloy was slightly pink and as such would only qualify as a 'red' gold but the one at 9 per cent zinc was judged to have a colour between that of a current 9 carat gold and that of the 18 carat standard alloy. Whilst this new alloy may constitute an improvement on the popular 10 per cent silver, 7.5 per cent zinc composition, it does not appear that possibilities for modifications in mechanical properties are exhausted. It is debatable, however, whether

Fig. 3 Scanning electron micrograph of a fracture surface in a 37.6 gold $/ 5$ silver $/ 10$ zinc $/ 47$ copper $/ 0.4$ silicon weight per cent cast alloy. The interdendritic space clearly remained unfilled after solidification because of insufficient eutectic liquid 
such an improvement is desirable in an alloy which is not produced primarily for its high strength. A harder alloy would be less susceptible to smearing and gold enrichment of the surface during polishing, a feature important for display. On the other hand, less wear and deterioration of colour in the abrasive conditions of service could be expected.

\section{Acknowledgements}

The author wishes to thank the International Gold Corporation Limited and the Chamber of Mines of South Africa for their financial support for this work and the Goldsmiths' Company Research Foundation for guidance throughout the course of the work. Thanks are also due to Mr. G. Reeves who performed almost all of the experimental work.

\section{References}

1 C. J. Smithells, 'The Metals Reference Book', 5th Edition, Butterworth, London and Boston, 1976

2 C. McCaul, R. Krohn and C. D'Antonio, Trans. Ant. Inst, Min. Metall. Eng., 1969, 245, 432-434

3 M. Pickus and I. Pickus, Met. Technol, 1943, 10, 1-7

4 R. Hultgren and L. Tarnepol, Trans. Am. Inst. Min. Metall. Eng., 1939, 133, 228-237

5 'Gold: Recovery, Properties and Applications', ed. by E. M. Wise, D. van Nostrand Co. Inc., Princeton, N.J., 1964

6 A. S. McDonald and G. H. Sistare, Gold Bull., 1978, 11, (3), 66-73

7 J. Leuser, Metall, 1949, 3, 105-110,128

8 'Electron l'robe Micro Analysis', ed. by J. J. B. Reed, Cambridge University Press, London, 1975

9 K. E. Saeger and J. Rodies, Gold Bull., 1977, 10, (1), 10-14

\title{
A New Text on the Applications of Gold
}

\author{
Gold Usage BY W. S. RAPSON AND (in part) T. GROENEWALD, Academic Press, London, 366 pages, $£, 12$
}

\section{K. E. Saeger}

\author{
Dr. E. Dürrwächter Doduco KG, Pforzheim, West Germany
}

Gold is most certainly one of the eternally fascinating subjects to read and write about. A large number of books, review articles, essays and scientific and technical papers have been published which deal with various aspects of this metal: its history, economic significance, extraction, properties, its special applications etc. Nevertheless, apart from Wise's monograph, which appeared in 1964 and has now been out of print for several years, comparatively little has been written with the aim of providing a complete and fairly detailed picture of all the more important applications of gold and its alloys. Furthermore, some trends in the use of gold have changed considerably during the last ten years. Therefore, a new book covering the usage of gold will definitely arouse a great deal of interest.

Even a very quick glance through the pages of the book by Rapson and Groenewald reveals that their work is much more than just a catalogue of the numerous applications which have developed for gold in addition to the traditional ones in coinage, jewellery, and restorative dentistry. Indeed, the title 'Gold Usage' is an understatement in that the book is a source of much more information than might be expected from its name.

The first chapter is devoted to a detailed survey of recent trends in production and consumption figures. A short second chapter deals with hoarding of, and investment in gold. Both these chapters are highly interesting, especially as some of the information given here, for instance the production figures of new gold in the U.S.S.R., is rather hard to come by for the great majority of those concerned with the use of gold. Even more valuable, however, are the contents of the following eight chapters in which the authors have succeeded in giving a comprehensive account of virtually every present-day application of the yellow metal as well as a large amount of information about why and how gold is used in each particular case. In order to achieve this, the authors had to work through a vast quantity of technical and scientific literature. Approximately 1200 books, papers and patents are quoted, in all probability practically the complete literature relevant for the user of gold, and much of it dating from the last fifteen years. Thus the important time span from the publication of Wise's book to the beginning of 1977 is also covered in detail. The only significant work not quoted appears, strangely enough, to be E. Raub's book 'Die Edelmetalle und ihre Legierungen'. This very complete coverage of the literature means that the book can be used as an efficient guide through the vast amount of published information on gold. In addition, most of the references are digested in such a manner that a fair insight into them is possible without the need to go back to the original sources. Another highly commendable feature of the book lies in the considerable effort which the authors have obviously made to describe complex features in such a way that even readers without any very thorough knowledge of metallurgy, chemistry and physics should be able to understand the important points. Rapson and Groenewald have produced a very readable book without over-simplification - not always an easy task in the fields of science and technology.

Some problems arise from the limitation in space combined with the wide scope of the book. One of them is that not every single application can be covered in great detail. The use of gold and its alloys in the production of electrical contacts, for instance, might have deserved somewhat more depth. However, in a book of this type, every specialist reading the chapter pertaining to his own field of activity tends to feel that some more detail would have been welcome. On the other hand one might query why the different strengthening mechanisms in some of the carat gold alloys are given a relatively broad discussion when reference to one or the other of the standard textbooks in physical metallurgy would have been more economic and just as helpful. These are minor points, however, which should not be taken too seriously. It is only fair to say that in the overwhelming majority of cases the authors have found a very satisfying balance between depth and compactness.

'Gold Usage' will be a reliable source of information for all those who work with gold or are interested in the unique properties of this metal and its alloys. It is carefully researched and well written. It makes fascinating reading, which is about the best that can be said of any book. 